\title{
O Círio de Nazaré (Pará, Brasil): relações entre o sagrado e o profano
}

\section{Círio of Nazaré (Pará, Brazil): relation between the sacred and profane celebrations}

\author{
Ricardo Frugoli (FRUGOLI, R.) ${ }^{*}$ \\ Marielys Siqueira Bueno (BUENO, M. S.) ${ }^{* *}$
}

\begin{abstract}
RESUMO - Desde o período colonial muitas festas brasileiras criam uma ponte simbólica entre o mundo sagrado e o profano. Atualmente, a forma mais expressiva dessa relação é o Círio de Nazaré (Belém, Pará, Brasil). Festa religiosa de gigantesca proporção, reconhecida entre as maiores do mundo, tem na procissão do Círio seu evento principal. A festa do Círio consta de uma sequência de rituais que faz dela, durante os quinze dias que se realiza, um polo de atração de devotos, visitantes e turistas. Paralelamente às práticas devocionais, vários eventos colocam em relação o sagrado e o profano entre os quais se destacam a procissão e a corda, o arraial e o 'almoço/banquete do Círio'. Assim, ao lado da expressão de fé e o sentimento de identidade e pertencimento que a devoção proporciona se tem a força da agregação e de coesão graças à comensalidade. Essa comunhão de emoção confirma a sociabilidade em ato que cimenta a vida social dos paraenses.
\end{abstract}

Palavras chave: Turismo religioso; Festa brasileira; Práticas devocionais; Sagrado e profano; Festa do Círio de Nazaré.

ABSTRACT - Since the colonial centuries many Brazilian celebrations create a symbolic connection bridge between the sacred and the profane environments. Nowadays, one of the most relevant expressions of this relationship is "Círio of Nazaré" in Belém, the capital of the Pará State. This is a huge religious event, one of the largest in the world, which has its apex in the Círio Procession. Círio of Nazaré consists in a sequence of rituals that last fifteen days and constitutes a special place for attraction of pilgrims, visitors and tourists. Besides these devotional practices, many others events are in close relation with sacred and profane environments especially the procession and the rope, and the camp and 'Lunch/Banquet of Círio'. Thus, together with this expression of faith and sense of identity and belonging, that devotion also provides the

\footnotetext{
* Formação: Graduação em Gastronomia e Mestrando em Hospitalidade na Universidade Anhembi Morumbi. Foi diretor de Formatação de Novos Produtos na Associação Brasileira dos Operadores de Turismo e consultor da Companhia Paraense de Turismo (PARATUR). Produtor musical e consultor na área de gastronomia, turismo e eventos. Endereço físico para correspondência: Rua Frei Caneca, 386, apto. 22 (Consolação). CEP: 1307-000 - São Paulo (SP) - Brasil. Telefone: (11) 3237-4656. E-mail: rfrugoli@singularproducoes.com.br.

** Formação: Graduação em Pedagogia (Bacharelado e Licenciatura) pela Faculdade de Filosofia Bernardo Sayão, Mestrado em Antropologia pela Universidade Federal de Goiás (UFG) e Doutorado em Sociologia pela Universidade de São Paulo (USP). Diplôme de Études approfondies en Anthropologie sociale, Université René Descartes - Paris V; Diplôme de Études Approfondies en Cinéma Anthropologiques, Unversité Nanterre - Paris X. Professora titular da Escola de Hospitalidade e Turismo da Universidade Anhembi Morumbi. Rua Casa do Ator, 294, $7^{\circ}$ andar (Vila Olímpia). CEP 04556-001 São Paulo (SP) - Brasil. Telefone: (11) 384703173. E-mail: marielysbueno@gmail.com
} 
strength and cohesion of the commensality. This communion of emotions is the bases and the strength of the social life residents.

Key words: Religious tourism; Brazilians religious celebrations; Devotional activities; Círio of Nazaré; Sacred and profane. 


\section{INTRODUÇÃO}

O Círio de Nazaré, a festa dos paraenses, é a primeira manifestação religiosa a ser reconhecida como bem cultural de natureza imaterial pelo Instituto de Patrimônio Histórico Nacional - IPHAN - em 2004, tendo se tornado também, patrimônio da humanidade na Oitava Reunião Anual do Comitê Intragovernamental para a Salvaguarda do Patrimônio Imaterial, da Organização das Nações Unidas para a Educação, a Ciência e a Cultura - UNESCO, em 4 de dezembro de 2013, que resolveu pela inclusão do Círio na Lista Representativa do Patrimônio Cultural da Humanidade (CÍRIO DE NAZARÉ É ..., 2013).

Trata-se de uma festa religiosa com mais de dois séculos de história que tem como motivação, a celebração e reafirmação da fé em Nossa Senhora de Nazaré. Podese dimensionar a importância da festa, pela mobilização de praticamente toda a população de Belém (Pará, Brasil) nos quinze dias de manifestações populares que, no registro da emoção e da devoção, tomam conta da cidade, além de atrair grande número de fiéis e turistas ${ }^{1}$. Sabe-se que as festas de uma maneira geral criam oportunidades de convivialidade, particularmente importantes para o homem contemporâneo, e no caso das festas religiosas, proporcionam a reafirmação da fé que nutre a esperança e o sentido para a vida, a proteção aos riscos, sobretudo do individualismo exacerbado que compromete o equilíbrio entre o público e o privado.

A cultura moderna estimula a emancipação dos vínculos sociais, concebidos como fardos a serem desvencilhados, o que aponta para a relevância do espaço público, especialmente quando cenário do compartilhamento festivo e religioso, para a geração de relações sociais, num tempo social que resulta da inserção do indivíduo em atividades participativas e inclusivas.

Assim, o momento das festas pode significar o reforço da alteridade, das relações com o 'outro', das diferenças que constituem a vida social e só podem ser efetivas na construção de relações empáticas em práticas sociais em espaços plurais e diversificados. Daí a importância social e cultural das festas, e em particular da festa do Círio de Nazaré aqui focalizada, por colocar em cena valores, artes e devoção, pois

\footnotetext{
${ }^{1}$ Disponível em: $<$ http://oglobo.globo.com/pais/em-belem-cirio-de-nazare-tem-publico-recorde-de-21-milhoes-de-fieis10353048>.
} 
como menciona Dumazedier (1988) uma festa é em geral um fenômeno de autoridade e coesão social.

Além disso, ainda é bom lembrar que a modernidade fragmentou o uso do espaço urbano provocando isolamento social, formas de exclusão e múltiplos obstáculos para os relacionamentos comunicativos. Tudo isso se soma aos efeitos da globalização no mundo contemporâneo - desemprego, emprego precário, exclusão, dentre outros; e ninguém questiona sobre a repercussão desses fatores nos espaços sociais e igualmente nos aspectos psicológicos do indivíduo.

No caso das festas, elas proporcionam a abertura de espaços nos quais uma comunidade, numa ruptura completa com a vida cotidiana se abre para um mundo sagrado e festivo. A festa, enquanto evento sagrado é vivido por uma comunidade como um momento intenso no qual a dispersão da vida cotidiana é substituída pelo agrupamento e concentração de energia e de seus membros. Segundo Villadary (1968) todas as festas são momentos de comunhão, momentos privilegiados onde uma comunidade exprime sua alegria acima da banalidade da vida comum. Na verdade, conforme afirma a autora, a festa abole o tempo. Essa temporalidade própria das festas explica a importância dessas cerimônias. No caso da festa do Círio fica evidente essa constatação a partir do que afirma essa autora, pois o espaço da cidade de certa forma se amplia e as pessoas, normalmente separadas, isoladas, se unem e se comunicam num mesmo fervor.

Por ser capaz de apreender o sentido profundo do pertencimento proporcionando um despertar da consciência de grupo, de comunidade, Amaral (1998) atribui às festas uma tríplice importância: a cultural, por colocar em cena valores, projetos, artes e devoções; como modelo de ação popular; e como produto turístico capaz de revitalizar e revigorar uma comunidade.

É pertinente observar que desde o período colonial em muitas festas brasileiras foi criada uma ponte simbólica entre o mundo sagrado e o mundo profano (AMARAL, 1998). As festas populares se caracterizando por manifestações nas quais o sagrado, o profano e o popular dividiam o espaço numa festiva comunhão de emoções que confirmava a sociabilidade numa ação que, de certa forma, proporcionava a identidade da vida social. Na verdade, essas festas transplantadas pelos colonizadores desde o início são marcadas pelas trocas culturais que, de certa forma, foram um elemento 
facilitador do processo adaptativo do modelo social europeu para as terras tropicais colonizadas (AMARAL, 1998).

Nesse processo, pela parceria que se instaurou entre o Estado e a Igreja, as festas tornaram-se aos poucos, simultaneamente, sagradas e profanas (AMARAL, 1998). Assim, observa-se no calendário de festividades coloniais, além dessa ligação sagrado/profano, num sentido mais amplo a produção da memória coletiva e, portanto, de identidade no tempo e no espaço.

Para Azevedo (2000, p. 34), "a memória coletiva é um instrumento revelador para as intenções e experiências individuais" e uma esfera de comunicação, causa e efeito de uma comunidade. "Ela abre espaço para a paixão, o afeto, a comunicação do ser/estar junto" (AZEVEDO, 2000, p. 34). Há, portanto, na temporalidade dessas práticas sociais, um caráter tradicional onde o passado e o presente se interconectam: "as manifestações culturais tradicionais trazem uma recorrente ponte transformadora entre o passado e o presente" (ALVIM, 2008, p. 24).

Essa conexão pode ser evidenciada na manifestação do Círio de Nazaré na qual os paraenses, no ato de compartilhar a memória dessa prática religiosa, construíram uma sólida tradição cultural. Hobsbawn e Ranger (apud ALVIM, 2008) ${ }^{2}$ afirma que as tradições vão sendo inventadas e reinventadas na intenção de preservarem certa conservação em relação ao passado diante das constantes transformações do presente. Com raízes no passado colonial, a procissão do Círio foi gradativamente ampliada pela inclusão de outras manifestações periféricas que, no dizer de Amaral (1998), transitam no limite da religiosidade.

Em face dessas considerações, além da pesquisa bibliográfica sobre o tema, desenvolveu-se uma pesquisa exploratória, de caráter qualitativo durante o biênio 20122013, mediante pesquisa em sites da internet, documentos e publicações científicas, e realização de visitas in loco em três períodos: 9 a 16 de outubro de 2012; 5 a 14 de outubro de 2013; e 25 a 29 de outubro de 2013. Essas visitas tiveram o objetivo primário de registrar, pela observação, as diferentes manifestações do Círio e os múltiplos relacionamentos de seus participantes, bem como perceber como se davam as relações entre as dimensões sagradas e profanas. Particularmente na visita à $221^{\mathrm{a}}$ edição desse evento em Belém (PA), realizada na segunda quinzena de outubro de 2013 e que

\footnotetext{
${ }^{2}$ HOBSBAWM, E.; RANGER, T. A invenção das tradições. Rio de Janeiro: Paz e Terra, 1984.
} 
reuniu 2,1 milhões de fiéis ${ }^{3}$, foram realizadas entrevistas abertas com representantes da comunidade e da organização, e com os participantes das diferentes dimensões da festa. Este artigo descreve a festa e analisa suas principais manifestações à luz da integração entre o sagrado e o profano.

\section{O CÍRIO DE NAZARÉ}

O festejar brasileiro, por suas características peculiares, pode ser considerado até mesmo, contrariamente à ideia de "alienação" que o envolve, como uma dimensão de aprendizado de cidadania e apropriação de sua história por parte do povo. (AMARAL, 1998, p. 8).

Os relatos sobre os eventos e festejos do Círio de Nazaré de Belém do Pará fazem referência à lenda do aparecimento da imagem da Nossa Senhora de Nazaré encontrada pelo caboclo Plácido José de Sousa (ALVES, 1980; CORRADI, 1997; IPHAN, 2006). A partir daí, uma sequência de rituais, com múltiplos desdobramentos, mobiliza a cidade de Belém do Pará durante quinze dias fazendo dela um polo de atração de romeiros e turistas de vários lugares de todo o mundo (CÍRIO DE NAZARÉ, 2013).

Segundo o IPHAN (2006), a devoção à Nossa Senhora de Nazaré é de origem portuguesa e possui uma longa e acidentada história. Acredita-se que ela foi esculpida por São José tendo a própria Virgem como modelo, tendo posteriormente passado sucessivamente pelas mãos de São Jerônimo, de Santo Agostinho, de um monge romano tendo finalmente parado nas mãos do rei Rodrigo dos visigodos, que derrotado pelos mouros, deixou, ao fugir, a imagem numa gruta onde ficou durante séculos até ser encontrada por pastores. A partir daí seu culto foi restabelecido. Ainda segundo o IPHAN (2006), Dom Fuas Roupinho foi salvo de cair no abismo por intercessão de Nossa Senhora de Nazaré e, agradecido, passou a propagar a devoção em Portugal.

Em Belém do Pará, a devoção à Nossa Senhora de Nazaré começa também a partir do achado da imagem por um caboclo nas margens de um igarapé. Autores como Alves (1980) e Corradi (1997) relatam o encontro da imagem pelo caboclo Plácido.

\footnotetext{
3 Disponível em: <http://oglobo.globo.com/pais/em-belem-cirio-de-nazare-tem-publico-recorde-de-21milhoes-de-fieis-10353048>.
} 
Comentam que ele caminhava nas matas da estrada de Utinga, hoje Avenida de Nazaré, e, com sede, buscou um igarapé onde pudesse se saciar e, então, descobriu, às margens do igarapé Murucutu, uma pequena imagem da Virgem; levou-a para casa, mas, no dia seguinte, ao acordar, viu que a imagem havia desaparecido. Ele voltou então ao local onde a havia encontrado e a Santa estava no mesmo lugar (IPHAN, 2006).

Segundo a mesma fonte, isso se repetiu várias vezes. Sabendo disso, o governador da época ordenou que a imagem fosse para o Palácio do Governo, onde deveria ficar sob intensa vigilância. Mesmo assim, no dia seguinte, o altar estava vazio. Impressionados os devotos resolveram construir uma ermida no local onde a Santa foi encontrada. Com o tempo o lugar foi atraindo pessoas de vários lugares. (IPHAN, 2006).

Amaral (1998) menciona que naquela época passavam por aquele local viajantes que vinham do Maranhão onde havia o culto de Nossa Senhora de Nazaré e, talvez, conforme ela, algum devoto tenha parado no igarapé e deixado a imagem nas pedras. Mas, como ela mesma comenta, isso não importa e o que conta é que a tradição desse achado envolve hoje toda a população paraense e mesmo de outros estados e pode se dizer que se tornou um dos fenômenos religiosos mais importantes do Brasil.

Mais tarde, o primeiro bispo do Pará, Dom Bartolomeu do Pilar visitou a modesta ermida e incentivou a devoção à Santa e, segundo o antropólogo Raimundo Heraldo Maués (IPHAN, 2006) ${ }^{4}$, a aproximação das autoridades na devoção à Virgem de Nazaré marcaria o início do controle eclesiástico sobre a devoção que se acentuou em 1793, quando o quinto bispo do Pará, Dom João Evangelista, oficializou a devoção.

$\mathrm{Na}$ mesma ocasião o presidente da província do Pará, Francisco de Sousa Coutinho, querendo fomentar o comércio regional, resolveu organizar uma feira para comercializar os produtos agrícolas e extrativistas, e estrategicamente determinou que a feira deveria ocorrer na mesma época em que os devotos homenageavam a Santa (AMARAL, 1998). Assim, considera-se pertinente observar que a oficialização da devoção pela Igreja e a feira organizada pelo presidente da Província ocorreram no mesmo ano. Inicia-se então o controle do Estado e da Igreja sobre a devoção de Nossa Senhora de Nazaré.

\footnotetext{
${ }^{4}$ MAUÉS, R. H. Padres, pajés, santos e festas: catolicismo popular e controle eclesiástico. Belém: CEJUP, 1995.
} 
Segundo o IPHAN (2006), na data marcada para a inauguração da feira, o presidente da Província adoeceu e, por causa disso, fez a seguinte promessa à Santa: caso ele se recuperasse e pudesse inaugurar a feira, levaria a imagem até o Palácio do Governo e, de lá, a conduziria, em grande estilo, de volta à igrejinha. Tendo se recuperado, cumpriu a promessa e o primeiro Círio foi acompanhado por quase dois mil soldados além da população de Belém e do interior do Estado.

Amaral (1998) fornece mais detalhes, observando que o governador carregou a imagem da Santa, apresentou-a à população e a entregou ao capelão do Palácio. Segundo a autora, teve início então a procissão com a tropa da cidade a frente do cortejo, seguida pelos esquadrões de cavalaria, batalhões de infantaria, duas filas de cavaleiros em traje de gala, várias seges e serpentinas transportando as senhoras. $\mathrm{O}$ palanquim, puxado por bois e ornamentado com flores e que conduzia o padre com a Santa, percorreu o trajeto cercado por devotos, pelo governador com um grande círio, pelos membros das Casas Civil e Militar (também uniformizados e a cavalo) e por último, as baterias de artilharia (AMARAL, 1998). Por motivo de segurança, a imagem original deixou de sair em 1969, ficando só no altar da Basílica, sendo então substituída pela 'imagem peregrina' que é uma réplica feita pelo italiano Giacomo Mussner (AMARAL, 1998).

No entanto, o Círio de Nazaré não se firmou e nem ganhou dimensões extraordinárias em função do prestígio oficial desse início. Segundo o IPHAN (2006), o Círio se impôs por si mesmo, graças à decisiva participação popular. As lendas em torno da imagem contribuíram para a sua popularidade bem como muitos milagres que lhes são atribuídos. É como se a recusa histórica da Santa em ficar encarcerada no Palácio do Governo simbolizasse, nessa atitude, o espaço de transgressão que marcaria o Círio ao longo de sua história. Também, de acordo com o IPHAN (2006), devem ser consideradas ainda as motivações e oportunidades profanas proporcionadas pelo evento do Círio.

Desta forma, a procissão do Círio apresenta um caráter de espetáculo organizado por corporações religiosas. Na verdade a festa de Nazaré, como muitas vezes é chamada, começa bem antes da data do evento, quando os responsáveis por sua organização se reúnem em comissões. Segundo Amaral (1998) a diretoria da festa consta de trinta membros que dividem as funções administrativas cujas principais são: a 
função de presidente sempre ocupada pelo vigário da paróquia de Nazaré; o coordenador; dois secretários; dois tesoureiros e um diretor de patrimônio. Os demais membros se distribuem em comissões que tratam da divulgação, da preparação da berlinda, da instalação dos serviços de som, da decoração da cidade, enfim, cobrem um campo bem amplo para que a festa seja bem sucedida.

Assim, a festa do Círio é constituída de uma sequência de eventos, mas segundo Amaral (1998) três deles são os mais significativos e, de certa forma, organizam os demais: as procissões do Círio; o arraial ou festa propriamente dita e o almoço do Círio, os quais são analisados a seguir.

\section{A PROCISSÃO E A CORDA}

Tratando-se de evento anual frequentado há anos pelos autores deste artigo, muitas das afirmações são fruto da observação, além de se embasarem em estudiosos que são citados neste tópico.

A procissão propriamente dita acontece no segundo domingo de outubro. Aliás, o mês de outubro transforma a cidade de Belém e, segundo Corradi (1997, p. 121) "a cada ano é inserida mais uma manifestação em homenagem à Santa alongando o tempo da procissão, e a distribuição dos eventos pela cidade. A autora registra a sequência das procissões mencionando que desde 1986 as festividades do Círio incluem a romaria rodo fluvial.

Na sexta feira à tarde os motoristas de carro prestam sua homenagem - a imagem é levada pelas principais avenidas da cidade e pelas rodovias federais e estaduais até o município de Ananindeua pernoitando na catedral local. No sábado pela manhã a imagem é levada através da Baia de Guajará acompanhada por um grande número de embarcações como homenagem dos pescadores. Chegando em terra firme se inicia a homenagem dos motoqueiros que acompanham a imagem da Santa até a Basílica. Depois a população se prepara para a Trasladação no sábado à noite, ocasião em que a imagem encontrada pelo caboclo Plácido sai da Capela Gentil Bittencourt e inicia uma procissão. A população acompanha com velas acesas fazendo o trajeto inverso do Círio que se realiza no domingo de manhã. 
Amaral (1998) observa que a procissão simboliza o mito do aparecimento e refaz a ligação iniciada em 1793 entre o Palácio do Governo e a Igreja de Nazaré e que essa procissão atrai devotos do interior do estado do Pará, de outros estados e mesmo do exterior ${ }^{5}$, além de turistas de diversas procedências.

É visível que mesmo que indiretamente, a população da cidade como um todo participa da procissão, inclusive grupos não católicos. Observou-se na visita in loco que um pastor da Assembleia de Deus, por exemplo, abria as portas do templo na Avenida Nazaré para oferecer café reforçado com pães, bolachas e bolos para os que participavam da procissão além de distribuir água aos peregrinos.

Pode-se dizer que os participantes do Círio podem ser agrupados em devotos e turistas, mas as fronteiras entre os espectadores e atores se diluem, pois se observa que grande emoção envolve todos os que acompanham a procissão. Nela, o paraense parece comungar com seus semelhantes, valores que dão sentido à sua existência religiosa. Desta forma, a festa se manifesta como um fato social de uma completa e ativa participação do paraense.

A Virgem é transportada numa luxuosa berlinda (figura 1). Além dos devotos que, descalços, disputam cada pedaço da corda, verificou-se ser muito forte a devoção das pessoas que acompanham a procissão ${ }^{6}$. Muitos levam miniaturas de casas, embarcações e outros objetos representando os milagres alcançados (figura 2).

\footnotetext{
${ }^{5}$ Em uma das entrevistas, uma paraense que mora na Dinamarca diz que embora não seja católica, sempre que pode vem participar com a família dos festejos do Círio.

${ }^{6}$ A corda puxada pelos promesseiros é um dos maiores ícones da grande procissão do Círio [...] tem 400 metros de comprimento, duas polegadas de diâmetro e é produzida em titan torcido de sisal oleado. Enfileirados, homens e mulheres puxam a corda que faz a berlinda com a imagem da Santa se movimentar (CÍRIO DE NAZARÉ, 2013, s. p.).
} 


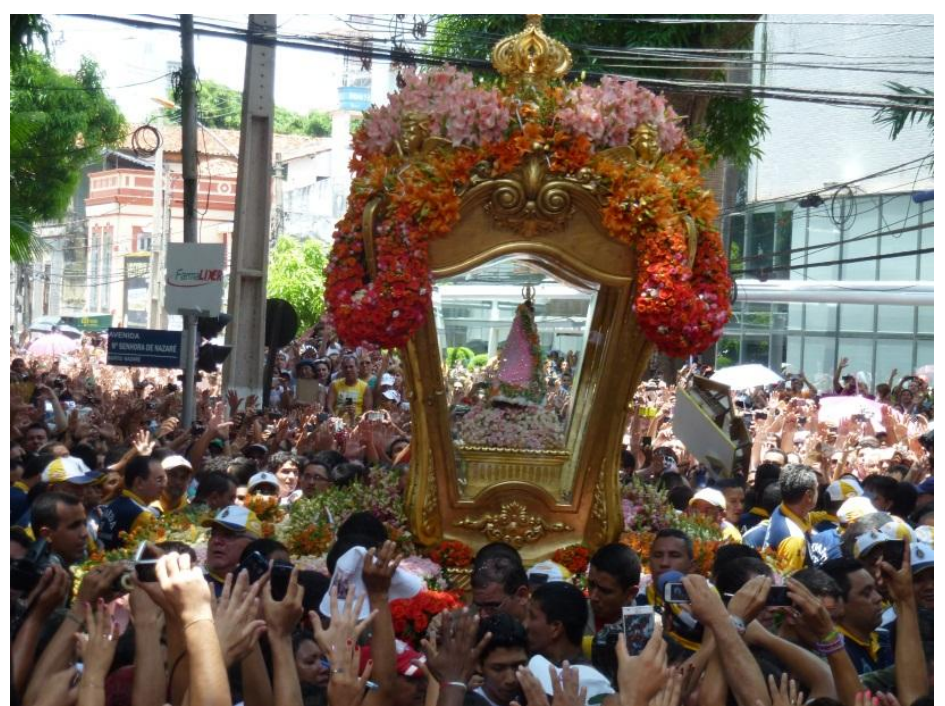

FIGURA 1 - ASPECTO DA PROCISSÃO COM A SANTA SENDO TRANSPORTADA NA BERLINDA

Foto: Ricardo Frugoli, 2013.

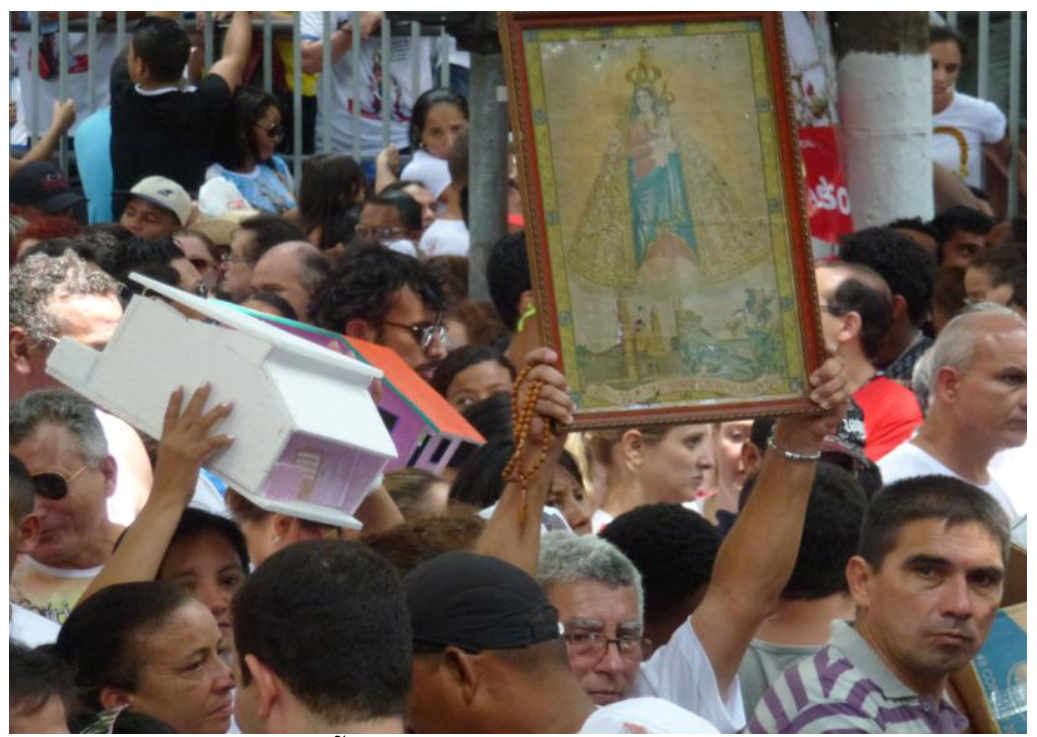

FIGURA 2 - ASPECTO DA PROCISSÃO COM DEVOTOS LEVANDO SEUS EX-VOTOS Foto: Ricardo Frugoli, 2013.

No 'carro dos milagres', observam-se representações de partes do corpo feitas em cera representando a cura de enfermidades por milagre da Santa. Corradi (1997) conta que esse carro representa as pessoas que se salvaram do naufrágio do navio São João Batista, em 1846, graças à ação milagrosa da Virgem. Outro carro que percorre o Círio é o dos 'anjos', no qual crianças vestidas de anjo cumprem promessas em agradecimento pelas graças recebidas.

Alves (1980) cita que a procissão do Círio consta de três espaços - o primeiro é ocupado pelas autoridades civis, militares, eclesiásticas, políticas e convidados que 
usam uma flâmula que permite entrar na corda. O outro segmento é composto pelo grupo de pessoas que seguram a corda. Para participar desse grupo é preciso chegar de madrugada para conseguir lugar. E para conseguir lugar na corda as pessoas se apertam, se empurram o quanto for possível, pois é muito importante segurar na corda. O terceiro segmento é composto pelos acompanhantes - uma gigantesca massa compacta de devotos. Ao longo do caminho percorrido pela procissão, pessoas ficam nas varandas das casas e apartamentos, todas com decorações para homenagear a Santa.

Na última festa, de 2013, em que se participou, em todo o trajeto a Santa recebia homenagens dos que aguardavam a sua passagem e esse é um momento em que se verifica intensa emoção. Todos participam dessa emoção, e todos, cientes do significado do evento se rendem à emoção e, como observa Amaral (1998), “as pessoas como que se transformam".

Amaral (1998) observa que em 1855, às vésperas da procissão, um transbordamento da baía transformou as ruas da cidade em grandes lamaçais e que devido a isso, o carro que conduzia a berlinda não conseguia passar. Alguém teve a ideia de desatrelar os bois e passar uma corda em volta da berlinda e puxar até desatolar. Puxada pelos fiéis, segundo a mesma fonte, a imagem saiu do atoleiro em frente ao mercado Ver-o-Peso e chegou até a ermida, prática essa que foi incorporada e a partir da qual os devotos passaram a usar a corda. Em 1868 a diretoria da festa oficializou o uso da corda no Círio e apesar de alguns protestos, a corda se transformou, com o tempo, na maior tradição da procissão (IPHAN, 2006).

Percebeu-se, por observação da festa em 2013, que as pessoas, desde a madrugada, esperam ansiosas conquistar um lugar na corda, fazendo o sacrifício tanto para conseguir lugar na corda quanto para fazer essa caminhada: descalças e comprimidas umas nas outras num calor escaldante (figura 3) para cumprir uma das mais árduas promessas. Pessoas ajudam a minimizar o desconforto oferecendo água e mesmo jogando água nos participantes para minimizar o calor. 


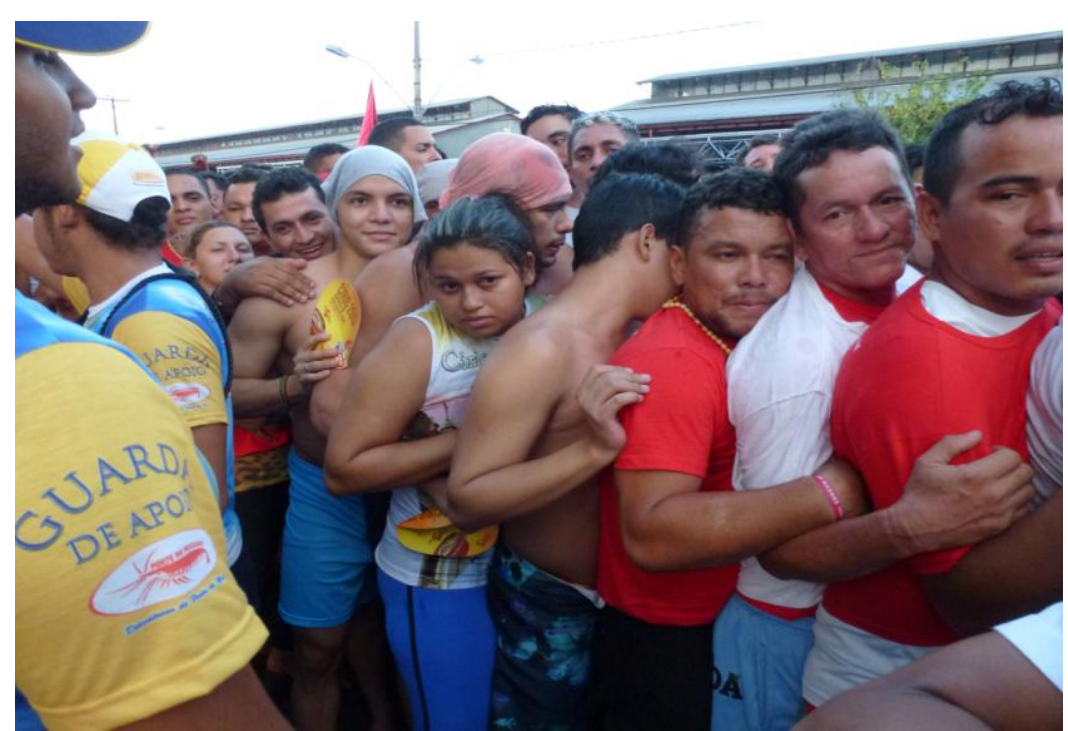

FIGURA 3 - CONCENTRAÇÃO DOS DEVOTOS E PROMESSEIROS (NA MADRUGADA) PARA CONSEGUIR TOCAR NA CORDA

Foto: Ricardo Frugoli, 2013.

Verificou-se por observação, que os devotos se empenham em conseguir lugar na corda e oferecem esse sacrifício à Santa ou para que seus pedidos sejam atendidos ou para agradecer as graças alcançadas. No fim da procissão a corda praticamente desaparece, pois todos disputam um pedaço dela para guardarem como relíquia.

\section{O ARRAIAL}

O arraial é o local de encontros, circulação de pessoas, de namoro e, em alguns momentos de "excessos" que, muitas vezes exige intervenção de agentes da diretoria ou mesmo da polícia. O primeiro arraial foi uma feira oficializada por Dom Francisco de Sousa Coutinho com o objetivo de aproveitar os festejos do Círio para incrementar a economia local.

Desde o primeiro Círio, em 1793, o arraial já fazia parte da festa Mariana. Inicialmente, ele era uma feira de produtos agrícolas que vendia frutas e animais de pequeno porte, para atrair a população do interior do estado. Em seguida, foram criadas as barracas com comidas típicas. E só então os jogos, teatros e outras atrações surgiram. Com essa mudança, a feira agrícola foi superada. (LOBÃO, 2013, s. p.)

Embora continue sendo um local com os mais variados tipos de comércio, o arraial tem um caráter festivo. É o local de festa dos devotos e dos não devotos, mas é 
entendido como parte da expressão da devoção à Santa. Nos momentos em que não acontecem as procissões ou cerimônias religiosas, as pessoas se dirigem para o arraial. Lá se encontram barracas com comidas típicas e uma grande variedade de produtos, jogos e danças. Entre as mercadorias do arraial, os brinquedos de miriti/buriti se tornaram presença obrigatória na quadra nazarena (FIGUEIREDO, 2013). São aves, barcos, bonecos e uma grande variedade de miniaturas feitas de caraná - a polpa dos galhos de uma palmeira (miriti ou buriti) e pintadas com cores fortes. Segundo Amaral (1998) as peças são fabricadas em Belém, mas a maior parte vem do município de Abaetetuba.

\footnotetext{
A chegada dos brinquedos em Belém já se transformou em mais uma atração da festa. No sábado chegam embarcações com os brinquedos e todos os vendedores se reúnem no Largo do Carmo, na Cidade Velha. Primeiro bairro da capital, onde os brinquedos são colocados em girândolas. Os vendedores ganham as ruas da cidade, dando um colorido único à festa. (AMARAL, 1988, p. 248).
}

No início as áreas do arraial eram leiloadas, mas, a partir de 1973 a diretoria decidiu fazer a seleção dos interessados e indicar a área de localização (AMARAL, 1988). Segundo Alves (1980), um professor universitário e empresário com grande experiência, foi indicado pela diretoria para organizar o arraial e evitar os desvios que não se coadunavam com o sentido da festividade.

$\mathrm{Na}$ área do arraial circulam diversas camadas sociais e conforme o seu espaço vai se distanciando da igreja nota-se a presença de pessoas mais simples de paraenses (ALVES, 1980). O princípio do arraial não se modificou, mas nele foram incorporadas manifestações culturais como danças folclóricas e música popular.

Tem havido um esforço, tanto da diretoria quanto das autoridades eclesiásticas, para manter a ordem e evitar as desordens e os excessos. Esse esforço conjunto parece manter o equilíbrio nessa dimensão profana da festa. Para Alves (1980, p. 79), a realização da festa parece demonstrar uma situação de "compromisso" entre as manifestações mais formais dirigidas pela autoridade religiosa e outras mais informais onde tem lugar a manifestação popular tal como o povo entende o que seja 'festa'. 


\section{O ALMOÇO DO CÍRIO}

No mito de origem do Círio verificou-se não haver nenhuma alusão à comida. No entanto, o almoço do Círio se consagrou como dimensão essencial nas comemorações do Círio e ganhou a força da identidade local (AMARAL, 1998). Esse evento, num primeiro momento tem a sua função social voltada para a família e amigos íntimos, mas tem também uma função ritual e simbólica de uma unidade social mais ampla com o ideal de confraternização e convivialidade que se opõe à realidade do individualismo cotidiano (AMARAL, 2005). No almoço celebra-se a solidariedade grupal - a alegria do encontro, quando as pessoas compartilham com familiares e amigos os valores que dão sentido a essa dimensão religiosa.

Apesar do almoço não pertencer à esfera do sagrado, não apresenta uma quebra absoluta entre o 'almoço' e o restante da experiência religiosa. Como comentou Cipriani (1988, p. 124) "tudo é impregnado simultaneamente de pragmatismo e idealismo".

No almoço observam-se comportamentos emocionais e afetivos com a santa padroeira. Tanto assim, que eles expressam essa proximidade na forma carinhosa de tratamento "Naza", "Nazinha" denotando a intimidade afetiva com a Santa.

O almoço do Círio, uma das principais atividades do ciclo de festejos, se inicia em seguida à passagem da Santa (CÍRIO DE NAZARÉ, 2013). Esse encontro tem um caráter familiar. Os parentes distantes vêm à festa para pagar promessas ou compartilhar a presença de todos nessa reunião anual. Participam também do almoço, chamado por eles de 'Natal paraense' amigos íntimos e convidados especiais.

A alegria do encontro impera nessa ocasião. $\mathrm{O}$ cardápio varia, mas dois pratos são obrigatórios, sem os quais não pode ser considerado Almoço do Círio - trata-se da maniçoba e o pato no tucupi; outros pratos podem ser servidos, mas esses dois pratos típicos do Pará são essenciais e representam símbolos identitários de crença compartilhada (ALVES, 2005). O preparo da maniçoba assume o caráter de um símbolo e de um ritual uma vez que exige um longo cozimento - de 6 a 7 dias, nos quais as famílias também se preparam para o compartilhamento com seus próximos e, nesse tempo, se refazem, ainda que simbolicamente, as relações que sustentam a família.

Boutaud (2004, p. 1318) discorre que "lugar de partilha, em épocas ordinárias, a mesa é também lugar de festa e de celebração do vínculo social e de convivência, mas 
também dos grandes momentos da vida". Assim, conforme ele, a comunidade se encontra e expressa sua capacidade de intercambiar.

É grande a importância do banquete para a vida daqueles que o realizam e dos que dele participam. A dimensão festiva do almoço/banquete enquanto manifestação cultural comunitária então é também muito importante. Cruz (2008, p. 20) menciona que a festa pode gerar vários produtos tanto materiais ou simplesmente significativos:

[...] o mais crucial e o mais geral desses produtos é, precisamente a produção de uma determinada identidade que é dada pelo compartilhamento do símbolo celebrado e que, portanto, se inscreve na memória coletiva como um valor coletivo, como a junção dos afetos e expectativas de indivíduos como um ponto comum que define a unidade dos participantes.

A comida então assume um caráter simbólico. A comida tem que ser especial e o almoço é marcado pela prodigalidade e a fartura que corresponde também à prodigalidade das bênçãos e das graças proporcionadas pela Virgem de Nazaré (IPHAN, 2006). No almoço do Círio, "percebe-se uma certa continuidade de algumas relações encontradas na procissão principal: formalidade e informalidade, sagrado e profano entre outros" (IPHAN, 2006, p. 53).

É importante apreender a função social da comensalidade, pois a convivialidade exerce um papel importante na dimensão das relações sociais pela sua dimensão agregadora que se estabelece numa dinâmica de compartilhamento. Maffesoli (1984; 2002) defende a mesa como lugar de comunicação evidenciando o papel vital da alimentação na formação e fortalecimento dos laços sociais.

Tais momentos são importantes, pois sem dúvida a preparação coletiva dos pratos típicos reforça a identidade da região e nutre o sentido de pertencimento a ela. É notável perceber que a cultural tradicional dessa região, por meio da sua comensalidade, revela uma acentuada vitalidade. Boutaud (2004, p. 1.221) de certa forma sintetiza assim a força agregadora da comensalidade:

O peso simbólico da comensalidade como construção do laço social e identitário, nos levou a reconhecer todo seu poder de encantamento, de fascinação, de arrebatamento: pela magia do ambiente, pela embriaguez do reencontro, pela catarse da linguagem ou do discurso. Tudo o que confere à comensalidade, seu ritmo, sua energia. 
O comer junto, o compartilhar da tradição ganha o caráter de um símbolo e a força de ritual. É uma dimensão do Círio que promove a consolidação dos vínculos sociais bem como promove o sentido de pertencimento e de identidade.

\title{
6 O AMÁlGAMA ENTRE O SAGRADO E O PROFANO
}

\begin{abstract}
O poder instituído tenta fazer uso da festa em seu favor, mas ela não se deixa capturar. A negociação entre os símbolos da festa e seu uso político é complexa, e ela não se rende, senão naquilo que considera necessário para atingir seus objetivos. (AMARAL, 1998, p. 285).
\end{abstract}

Verificou-se que com o desenvolvimento das festividades do Círio, um número crescente de eventos foram sendo incorporados interligando o mundo simbólico cristão e o profano. Verificou-se também que se fez necessária a intervenção na infraestrutura da cidade para a recepção dos turistas e devotos, gerando empregos e também um mercado de bens simbólicos e materiais criados a partir do referencial da Festa do Círio: - velas, imagens, lembranças. Com isso verifica-se a ampliação das atividades ligadas às festividades que, por sua vez, revertem em benefícios para a cidade, pois mercadorias produzidas durante o ano todo recebem um mercado consumidor capaz de esgotá-las durante o período do Círio.

Esse aspecto confirma a hipótese de Amaral (1998) segundo a qual as festas brasileiras vêm se tornando um excelente negócio pelo seu forte apelo turístico, especialmente quando representam aspectos regionais, mitos religiosos. Daí a importância das festas, que para essa autora, coloca em cena os valores, os projetos e a devoção do povo brasileiro.

Desde a sua origem, a festa do Círio de Nazaré foi passando por grandes transformações, mas não perdeu o seu caráter confraternizador e ainda congrega a população de maneira abrangente, sendo um acontecimento que envolve direta ou indiretamente a população além dos limites do Estado do Pará. A força da fé faz com que o Círio promova também a economia, o desenvolvimento e o turismo gerando empregos e, além disso, desde sua institucionalização, promove uma intensa comunhão entre os membros da comunidade. 
A mídia intensifica a dimensão dos eventos através de espaços cada vez mais amplos na divulgação das informações de todos os aspectos do Círio (SOUZA, 2006). As transmissões ocupam um amplo espaço: cadernos especiais, edições específicas tanto em veículos impressos como eletrônicos divulgam todas as dimensões da festa e estimulam a participação nos eventos (SOUZA, 2006).

$\mathrm{O}$ conjunto das atividades promove o enraizamento, o sentimento de pertencimento e, em função do uso coletivo e participativo do espaço público, criam-se situações que promovem a convivialidade, particularmente importantes para o homem contemporâneo, que na dimensão do cotidiano, vê reduzidas as experiências comunitárias devido ao individualismo estrutural da sociedade moderna.

Com o passar dos anos, apesar de todos os acréscimos que foram incorporados nas manifestações do Círio, não se alterou o fervor da devoção e as dimensões profanas que a tradição popular consagrou guardando a mesma função agregadora e identitária. A mobilização da comunidade através das atividades tanto devocionais quanto de confraternização reafirmam o sentimento de comunhão que nutre, desenvolve e amplia os vínculos sociais.

Observa-se que em ambas as dimensões - a sagrada e a profana, os paraenses revivem e colocam em cena a história da Santa e, como já foi dito, com ela nutrem uma relação de proximidade afetiva com uma intimidade respeitosa e carinhosa - a 'tia Naza' a 'Nazinha', evidenciando a profunda e próxima relação entre os devotos e a Santa.

Reforça-se o pensamento de Amaral (1998) de que o povo paraense faz uma verdadeira imersão no sentido da festa. Pela devoção, pela intensa emoção dos rituais, pelo compartilhamento da mesa farta, 'devocionalmente preparada', os paraenses vivem uma experiência única e inesquecível que os une e os identifica enquanto comunidade.

\section{CONSIDERAÇÕES FINAIS}

No artigo se procurou evidenciar, por meio do exemplo da festa e do almoço do Círio de Nazaré, Belém do Pará, a grande potencialidade das festas de caráter popular, que combinam o sagrado e o profano, na organização e muitas vezes redefinição da vida 
social. Para tanto, utilizou-se de pesquisa empírica e da observação in loco, em mais de uma versão anual da festa, ao lado do exame da bibliografia pertinente.

Procurou-se mostrar que há mais de dois séculos, a festa do Círio de Nazaré mobiliza devotos para agradecer as bênçãos recebidas, fazer pedidos à Santa e invocar sua proteção. Ao longo dos anos, as relações sociais que estão na base dessas manifestações foram se fortalecendo e a sua expansão e os acréscimos que foram sendo introduzidos não comprometeram os seus aspectos positivos e vigorosos. Apesar do grande número de público que aflui à festa e, apesar das dimensões profanas, a fé e a devoção mantiveram a sua força agregadora da população.

Os festejos do Círio oscilam entre o polo religioso no qual a população comunga sua fé e celebra sua devoção e o polo profano que oferece a possibilidade de uma participação ativa na qual se criam momentos para a convivialidade e o compartilhamento festivo de seus valores. Se o sagrado propicia o conforto espiritual ou psicológico da proteção e do auxílio da Santa, o profano, através das manifestações festivas, promove a participação coletiva que une e integra a comunidade. Tudo vai permitir falar mais vigorosamente sobre as tradições e re-dinamizar as relações sociais e os valores comuns.

Tanto no aspecto religioso quanto na dimensão profana, a festa do Círio supõe uma expansividade coletiva cuja função primordial é estabelecer relações sociais. Se por um lado o espaço das procissões e eventos religiosos sacralizam os espaços da cidade, por outro as relações sociais através da participação em eventos como o almoço do Círio, por exemplo, ganham o caráter solene de pertencimento coletivo.

O que se observa, também, é a força da participação da população. Em várias ocasiões a participação popular resistiu ao controle excessivo tanto da Igreja quanto do Estado, encontrando formas de exprimir vigorosamente sua história, seus valores, suas alegrias.

E, ao sentir a intensidade da força da fé e da devoção nos eventos religiosos e ao compartilhar da alegria e da efervescência das festas, pode-se concluir que no Círio de Nazaré há um clima que dilui as barreiras e fronteiras entre o sagrado e o profano, entre o rico e o pobre, entre o católico e os membros de outras denominações. E, sobretudo, em ambas as dimensões se privilegiam o coletivo e a convivialidade em oposição ao individualismo engendrado pelas características urbanas. 


\section{REFERÊNCIAS}

ALVES, I. O carnaval devoto: um estudo sobre a festa de Nazaré, em Belém. Petrópolis: Vozes, 1980.

ALVES, I.; ALVES, I. A festiva devoção no Círio de Nossa Senhora de Nazaré. Estudos Avançados. 2005, v.1 9, n. 54, p. 315-332.

ALVIM, V. R. A tradição e a reinvenção em um olhar sobre a festa do Congado. Cadernos do JIPE-CIT - Grupo Interdisciplinar de Pesquisa e Extensão em Contemporaneidade, Imaginário e Teatralidade. Salvador, n. 20, maio 2008, p. 18-27.

AMARAL, R. de C. de M. P. Festa à Brasileira: significados do festejar num país 'que não é sério'. Tese (Doutorado em Antropologia Social) - Faculdade de Filosofia, Ciências e Letras, Universidade de São Paulo, São Paulo, 1998.

AZEVEDO, L. E. C. Boi Bumbá de Parintins: cenários na pós-modernidade e sua inserção no marketing cultural. Dissertação (Mestrado em Administração) Universidade Federal de João Pessoa, João Pessoa, 2000.

BOUTAUD, J. J. Comensalité, le partage de la table. In: MONTANDON, A. (Ed.). Le livre de l'hospitalité. Paris: Bayard, 2004.

CIPRIANI, R. Experimentos com histórias de vida. In: VON SIMSON, O. de M. (Org.) Itália/Brasil, Enciclopédia Aberta de Ciências Sociais. São Paulo: Vértice, 1988.

CÍRIO DE NAZARÉ. Belém, Paróquia de Nossa Senhora de Nazaré, 2013. Disponível em: < http://www.ciriodenazare.com.br>. Acesso em: 11/11/2013.

CÍRIO de Nazaré é declarado patrimônio cultural da humanidade. Diário do Pará. Belém, 4 dez. 2013. Disponível em: <http://g1.globo.com/pa/para/noticia/2013/12/cirio-de-nazare-edeclarado-patrimonio-cultural-da-humanidade.html>. Acesso em: 5/12/2013.

CORRADI, A. Círio de Nossa Senhora de Nazaré - A divulgação como grandeza da fé. Anuário de Comunicação Regional Unesco/Umesp. São Bernardo do Campo, v. 1, n. 1, 1997, p. 119-133.

CRUZ. M. S. Festa Popular, Mídia e Identidade. Itinerários. Revista Científica de Turismo. São Luís, Maranhão, v. 3, junho. 2008, p. 17-32.

DUMAZEDIER, J. Revolution culturelle du Temps Libre - 1968 - 1988. Revue Française de Sociologie. Paris, Mérediens, Klincksieck, v. 32, n.1, p. 143-145, 1991.

FIGUEIREDO, V. L. M. A fé que caminha sobre a terra e as águas: os roteiros devocionais do Círio de Nazaré e suas manifestações espaciais. Fortaleza (Mestrado em Geografia) - UECE, 2013. 
IPHAN - Instituto do Patrimônio Histórico e Artístico Nacional. Círio de Nazaré. Rio de Janeiro: Iphan, 2006. (Dossiê Iphan, 1).

LOBÃO, A. C. Círio - Histórico. Belém: Fundação Nazaré de Comunicação. Disponível em:

$<$ http://www.fundacaonazare.com.br/novoportal/?action=Canal.interna\&oCanal=10\&id $=138 \&$ classe $=\mathrm{M}>$. Acesso em: nov./2013.

MAFFESOLI, M. A conquista do presente. Trad. Márcia de C. de Sá Cavalcante. Rio de Janeiro: Rocco, 1984.

Mesa espaço de comunicação. In: DIAS, C. M. de M. (Org.). Hospitalidade: reflexões e perspectivas. São Paulo: Editora Manole, 2002.

SOUZA, M. I. A. R. O Círio de Nazaré: a mídia em prol do desenvolvimento regional. In: CONGRESSO MULTIDISCIPLINAR PARA O DESENVOLVIMENTO REGIONAL, 1. Anais... São Bernardo: UMESP, 2006, s. p.

VILLADARY, A. Fête et vie quotidienne. Paris: Ouvrières, 1968. (Col. L'Evolution de la Vie sociale).

Recebido em: 20-12-2013.

Aprovado em: 31-12-2013. 